\title{
Influence of In-Situ Nanoprecipitation on Constant Load Deformation in the Glass Transition Region of a $\mathrm{Cu}_{60} \mathrm{Zr}_{30} \mathrm{Ti}_{10}$ Bulk Metallic Glass
}

\author{
Hidemi Kato $^{1}$, Dmitri V. Louzguine ${ }^{1}$, Akihisa Inoue ${ }^{1}$, Hyoung Seop Kim ${ }^{2}$ and Ho-Sou Chen ${ }^{3}$ \\ ${ }^{1}$ Institute for Materials Research, Tohoku University, Sendai 980-8577, Japan \\ ${ }^{2}$ Department of Metallurgical Engineering, Chungnam National University, Daejeon 305-764, Korea \\ ${ }^{3}$ (Ret.) Bell Laboratories, Lucent Technologies, Murray Hill, New Jersey 17974, USA
}

\begin{abstract}
Nonlinear viscoelasticity influenced by an in situ nanocrystallization under constant load compression at the glass transition temperature, $T_{\mathrm{g}}$, is investigated with a $\mathrm{Cu}_{60} \mathrm{Zr}_{30} \mathrm{Ti}_{10}$ (at \%) bulk metallic glass (BMG). The experimental curves showed the characteristics, softening and subsequent recovering phenomena which have been observed in a 'stable' Zr-based BMG and also hardening through whole deformation process due to the in situ nanoprecipitation in the glass matrix. These characteristics are fairly reproduced by the fictive stress model extended by the Johnson-Mehl-Avrami (JMA) equation and mixture rule for respectively expressing influences of the Newtonian viscosity and of Young's modulus and critical stress on volume fraction of the nanoprecipitates.
\end{abstract}

(Received November 28, 2003; Accepted May 10, 2004)

Keywords: bulk metallic glass, non-Newtonian flow, in situ nanocrystallization, fictive stress model

\section{Introduction}

A number of bulk metallic glasses (BMGs) have been formed by a copper mould casting technique in Mg-Ln-TM, ${ }^{1)}$ $\left.\mathrm{Ln}-\mathrm{Al}-\mathrm{TM},{ }^{2)} \mathrm{Zr}-\mathrm{Al}-\mathrm{TM},{ }^{3}{ }^{3} \mathrm{Zr}-(\mathrm{Ti}, \mathrm{Nb}, \mathrm{Pd})-\mathrm{Al}-\mathrm{TM},{ }^{4}\right) \mathrm{Zr}-\mathrm{Ti}-$ $\mathrm{TM}-\mathrm{Be},{ }^{5)} \mathrm{Fe}-(\mathrm{Al}, \mathrm{Ga})-(\mathrm{P}, \mathrm{C}, \mathrm{B}, \mathrm{Si}),{ }^{6)} \mathrm{Pd}-\mathrm{Cu}-\mathrm{Ni}-\mathrm{P},{ }^{7)}$ (Fe, Co, $\mathrm{Ni})-(\mathrm{Zr}-, \mathrm{Nb}, \mathrm{Ta})-\mathrm{B},{ }^{8)} \mathrm{Fe}-\mathrm{Co}-(\mathrm{Zr}, \mathrm{Nb})-(\mathrm{Mo}, \mathrm{W})-\mathrm{B}^{9)}$ and $\mathrm{Co}-$ $\mathrm{Fe}-\mathrm{Ta}-\mathrm{B}^{10)}$ alloy systems, and some of them have already gained application fields. In order to open up new application fields of the BMG, many efforts were done for designing its composite materials. One of the composite designs, glass matrix and nanocrystalline particle mixed structure alloy has been prepared by the copper mould cast technique with subsequent heat treatment at the supercooled liquid region (SLR) to induce devitrification. ${ }^{11)}$ This composite sometimes shows higher fracture strength or plasticity at room temperature than the monolithic BMG without annealing. ${ }^{11,12)}$ Because this composite is prepared using devitrification in the SLR of the cast monolithic BMG, the viscous flow at the SLR with the in situ devirtification is useful for manufacturing its products. In this process, the material is prone to be subjected to extreme high strain rates or high stresses, and the viscosity becomes the non-Newtonian state. Therefore, understanding of the transition between the Newtoniannon-Newtonian viscous flows of a supercooled liquid of BMGs influenced by the in situ devitrification is of both scientific and technological importance.

In this paper, we intend to investigate experimentally mechanical response (e.g., stress, strain and viscosity) of a $\mathrm{Cu}_{60} \mathrm{Zr}_{30} \mathrm{Ti}_{10} \mathrm{BMG}^{13-16)}$ during nonlinear viscoelasticity influenced by the in situ nanocarystallization under constant load compression at $T_{\mathrm{g}}$, and also to reproduce it by a calculation model based on the fictive stress model. ${ }^{17)}$

\section{Experimental}

For compressive tests, cylindrical samples, $2.5 \mathrm{~mm}$ in diameter and $5 \mathrm{~mm}$ in length (aspect ratio 2.0), were cut from $\mathrm{Cu}_{60} \mathrm{Zr}_{30} \mathrm{Ti}_{10}$ cast rods. The glass transition temperature, $T_{\mathrm{g}}$, and onset crystallization temperature, $T_{\mathrm{x}}$, were determined to be $708 \mathrm{~K}$ and $740 \mathrm{~K}$, respectively using a differential scanning calorimeter (Seiko DSC 6300) at a heating rate of $0.33 \mathrm{~K} / \mathrm{s}$. The high temperature compression tests were conducted isothermally at $T=708 \mathrm{~K}\left(=T_{\mathrm{g}}\right)$ in a purified argon atmosphere by an Instron type machine. The samples were inserted between $\mathrm{Al}_{2} \mathrm{O}_{3}$ plates toughened by $\mathrm{ZrO}_{2}$ in the machine, and were heated to the test temperature at a heating rate of $0.33 \mathrm{~K} / \mathrm{s}$ and hold for $180 \mathrm{~s}$ for thermal equilibrium, then, compressive tests were started. Transmission electron microscopy (TEM) was carried out using a JEOL-JEM3000F microscope operating at $300 \mathrm{kV}$. Samples for the TEM observation are prepared by an ion-polishing technique.

\section{Results and Discussion}

3.1 Structure of a $\mathrm{Cu}_{60} \mathrm{Zr}_{30} \mathrm{Ti}_{10}$ BMG at as cast state and nanocrystallization by isothermal annealing at $T_{\mathrm{g}}$

Figure 1 shows a bright-field TEM image of a $\mathrm{Cu}_{60} \mathrm{Zr}_{30^{-}}$ $\mathrm{Ti}_{10}$ BMG as cast state. The sample consists of two phases, glassy matrix and homogeneously dispersing particles in an average diameter of $\sim 10 \mathrm{~nm}$. By selected area electron diffraction (SAED) pattern taken at $300 \mathrm{kV}$ inserted in Fig. 1, the particles have a fcc-structure with lattice parameter of $4.15 \mathrm{~nm}$. And by nano beam EDX analysis, average compositions (at \%) of the matrix metallic glass and the nanoparticle phases are respectively determined to be $\mathrm{Cu}_{44.0^{-}}$ $\mathrm{Zr}_{45.6} \mathrm{Ti}_{10.4}$ and $\mathrm{Cu}_{70.5} \mathrm{Zr}_{24.3} \mathrm{Ti}_{5.2}$ (hereafter $\mathrm{Cu}$-rich phase). The nanoparticle is unknown phase therefore its volume fraction, $\phi_{\mathrm{Q}}$, can not be estimated directly.

Figures 2(a) and (b) shows DSC curves and the corresponding XRD patterns of the $\mathrm{Cu}_{60} \mathrm{Zr}_{30} \mathrm{Ti}_{10}$ BMGs annealed isothermally at $T=708 \mathrm{~K}$ for various times. Isothermal annealing at $T=708 \mathrm{~K}\left(=T_{\mathrm{g}}\right)$ enhances phase transformation of the first exothermic peak in the DSC curve. But no apparent peak diffracted from the new phase is observable and it just influences the half width of the halo peak around $2 \theta$ of 40 degrees in XRD patterns in Fig. 2(b). Figure 3 shows a 


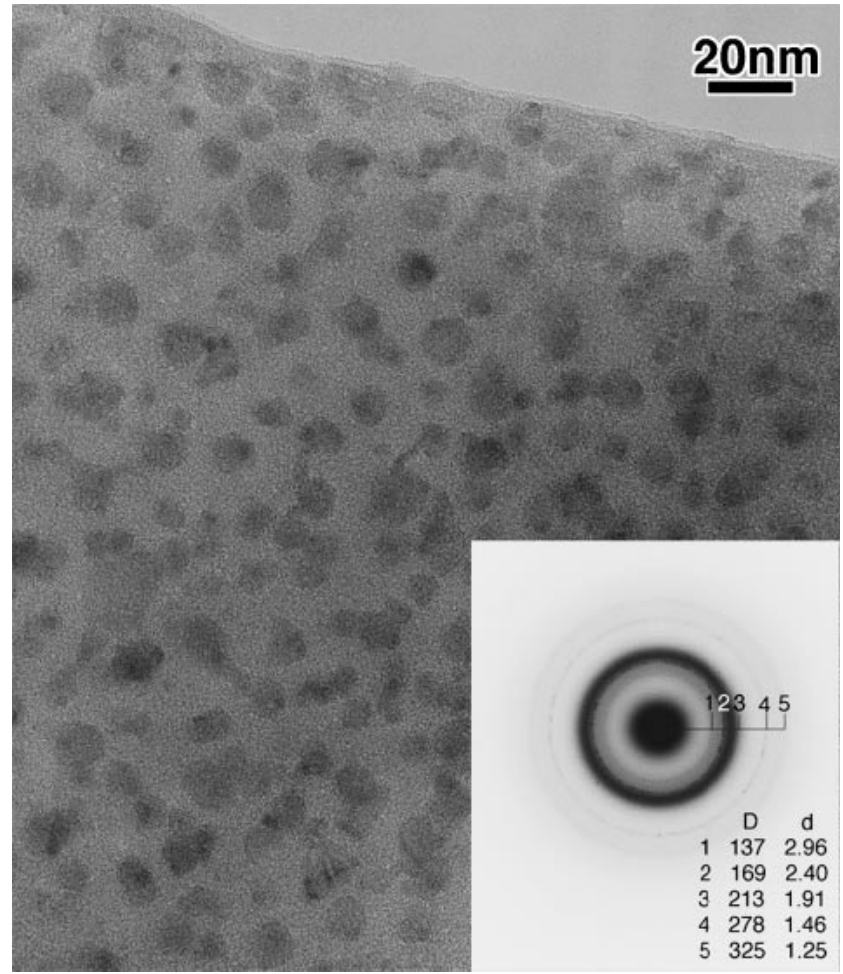

Fig. 1 Bright field transmission electron microscopic (TEM) image of an as-cast $\mathrm{Cu}_{60} \mathrm{Zr}_{30} \mathrm{Ti}_{10}$ bulk metallic glass. Its electron diffraction pattern is inserted in Fig. 1.

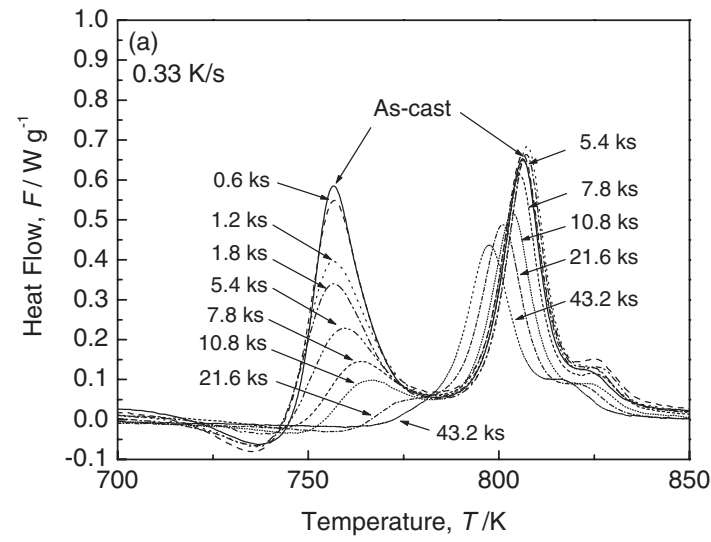

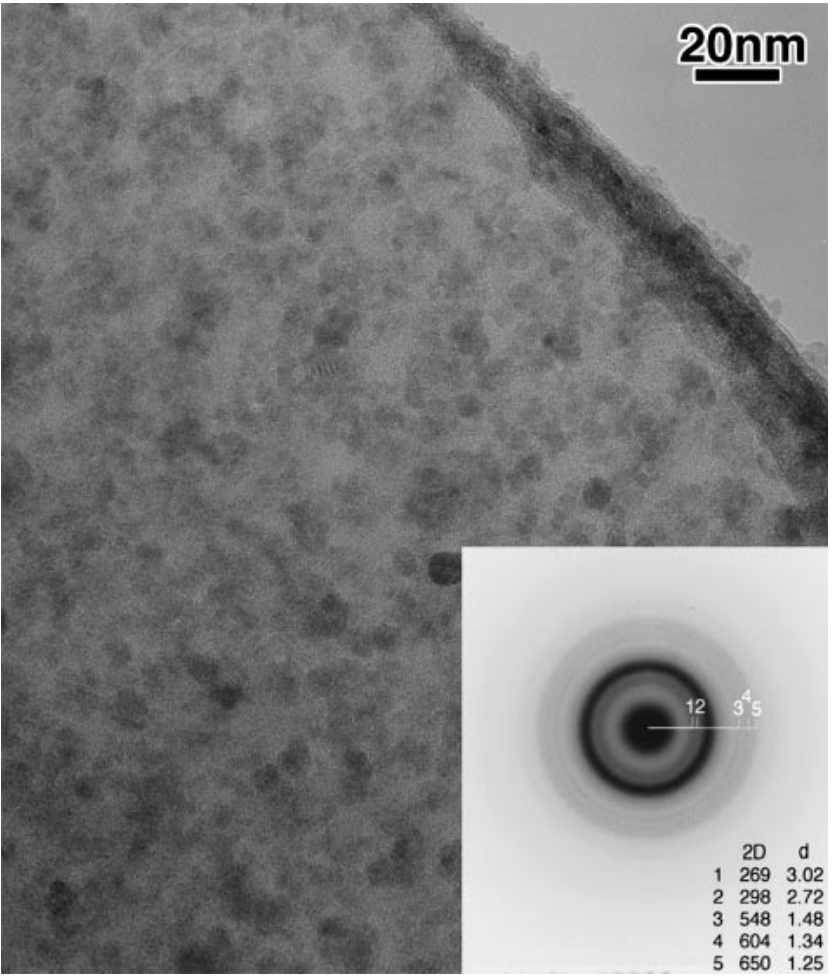

Fig. 3 Bright field transmission electron microscopic (TEM) image of a $\mathrm{Cu}_{60} \mathrm{Zr}_{30} \mathrm{Ti}_{10}$ bulk metallic glass isothermally annealed at $T=708 \mathrm{~K}$ for $7.8 \mathrm{ks}$. Its electron diffraction pattern is inserted in Fig. 3.

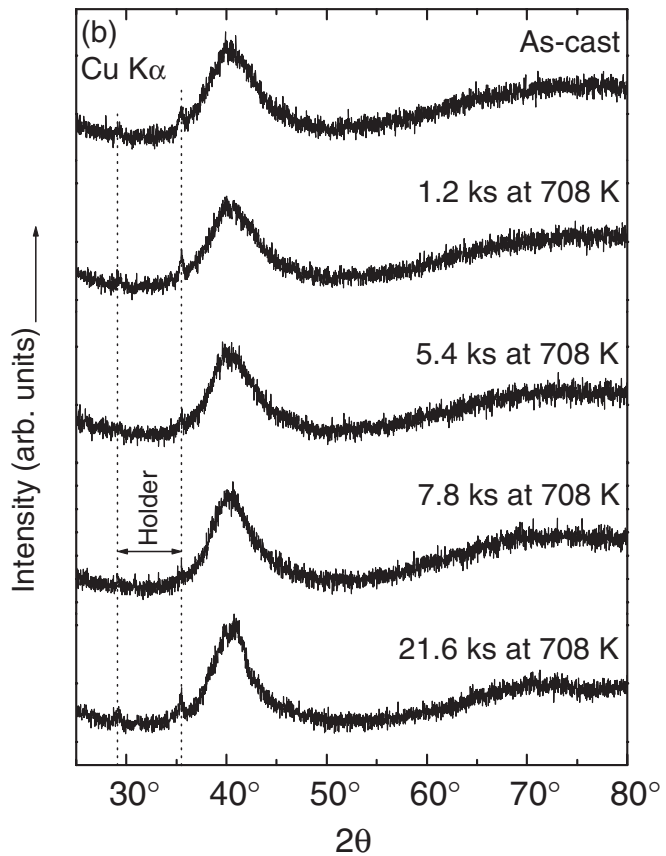

Fig. 2 Differential scanning calorimetric (DSC) curves at a heating rate of $0.33 \mathrm{~K} / \mathrm{s}$ (a) and X-ray diffraction (XRD) patterns (b) of $\mathrm{Cu}_{60} \mathrm{Zr}_{30} \mathrm{Ti}_{10}$ bulk metallic glasses isothermally annealed at $T=708 \mathrm{~K}$ for 0 (= as-cast), 1.2, 5.4, 7.8 and $21.6 \mathrm{ks}$. Peaks at $2 \theta$ of 28 and 36 degree are diffracted from a sample holder.

bright-field image of $\mathrm{Cu}_{60} \mathrm{Zr}_{30} \mathrm{Ti}_{10}$ BMG annealed isothermally at $T=708 \mathrm{~K}$ for $7.8 \mathrm{ks}$. In addition to the nanoparticles of the $\mathrm{Cu}$-rich phase which have already existed at as-cast state, one can easily see finer particles in average diameter of $\sim 5 \mathrm{~nm}$ precipitated around the $\mathrm{Cu}$-rich phase. The new phase cannot be identified by the SAED pattern inserted in Fig. 3, therefore it is considered to be unknown nanocrystalline phase. The phase transformation of the first exothermic peak in DSC curve is nanocrystallization from the matrix metallic glass around the $\mathrm{Cu}$-rich phase. The transition kinetics from the glassy matrix phase to the nanocrystalline phase was examined in the crystallization reaction during isothermal 


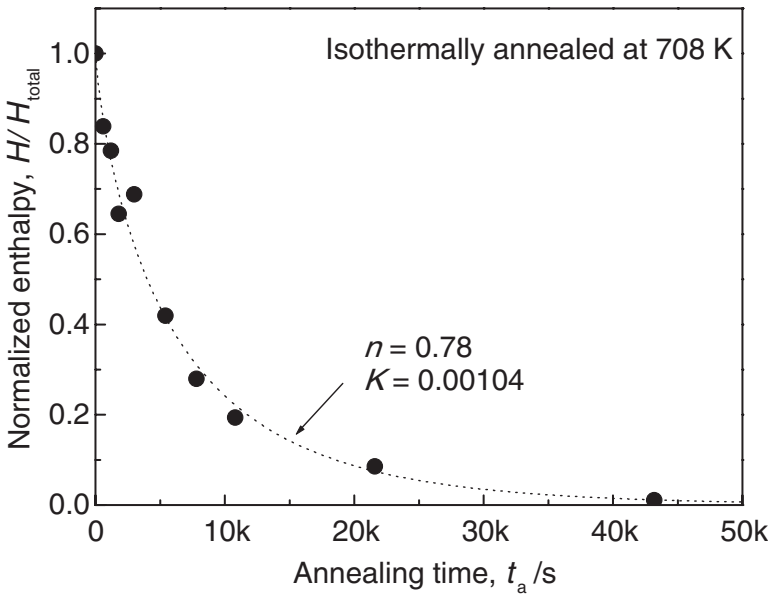

Fig. 4 Dependence of the normalized heat release, $H / H_{\text {total }}$, which corresponds to the first exothermic peak in the DSC curve of a $\mathrm{Cu}_{60} \mathrm{Zr}_{30} \mathrm{Ti}_{10}$ bulk metallic glass on annealing time, $t_{\mathrm{a}}$, isothermally at $T=708 \mathrm{~K}$. The $n$ and $K$ are the Avrami exponent and a fitting parameter, respectively.

annealing at $T=708 \mathrm{~K}\left(\sim T_{\mathrm{g}}\right)$. Figure 4 shows change in the normalized enthalpy, $H / H_{\text {total }}$, with various annealing times, $t_{\mathrm{a}}$, where $H$ and $H_{\text {total }}$ are respectively enthalpies of the first exothermic peak of annealed and as-cast samples. By fitting with the Johnson-Mehl-Avrami (JMA) equation, ${ }^{18)}$

$$
\frac{H}{H_{\text {total }}}=\exp \left(-K \cdot t_{\mathrm{a}}{ }^{n}\right)
$$

the parameters, $K$ and $n$, are determined to $1.04 \times 10^{-3}$ and 0.78 , respectively. The $n$ value ranges from 2 to 3 in a previous paper ${ }^{19)}$ on other metallic glasses. With comparing them, the $n$ value of the present work is low and means the nanocrystallization originated by inhomogeneous nucleation sites mainly around the quenched-in particles. Considering the lower present annealing temperature of $T_{\mathrm{g}}$, than other works, this behavior seems to be fair.

\subsection{Compressive constant load deformations of the $\mathrm{Cu}_{60} \mathrm{Zr}_{30} \mathrm{Ti}_{10}$ BMG at $T_{\mathrm{g}}$}

In the strict sense, the as-cast $\mathrm{Cu}_{60} \mathrm{Zr}_{30} \mathrm{Ti}_{10}$ rod is a nanocomposite material. But as shown in Fig. 2(a), this material shows the glass transition behavior and temperature span between the onset temperatures of the glass transition and crystallization can be estimated to $\sim 30 \mathrm{~K}$ due to the metallic glass matrix. Therefore this material keeps good workability and deforms homogeneously with viscous flow above $T_{\mathrm{g}}$. The heating this material above $T_{\mathrm{g}}$ brings about high workability and concurrently nanocrystallization mentioned in the previous section. The nanoprecipitation must disturb the viscous flow of the matrix phase, and results in decrease in workability of the material. However, the nanoparticles enhance strength of the material at room temperature. Therefore it becomes important to investigate influence of the in situ nanocrystallization on viscous flow behavior at the glass transition region.

\subsubsection{Dependence of viscous flow behaviors on constant applied load}

Figure 5(a) shows experimental results of strain-time
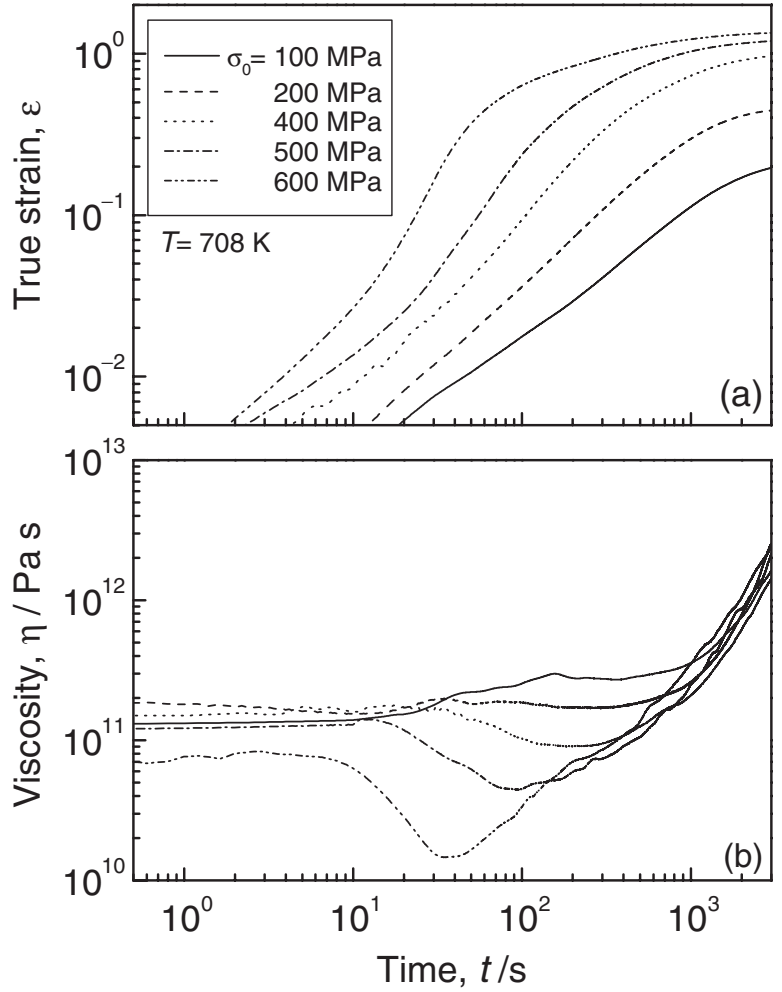

Fig. 5 Experimental strain-time $(\log \varepsilon-\log t)$ (a) and viscosity-time $(\log \eta$ $\log t$ ) (b) of a $\mathrm{Cu}_{60} \mathrm{Zr}_{30} \mathrm{Ti}_{10}$ bulk metallic glass under various constant compressive loads, $F$, of $50 \mathrm{kgf}$ ( $=$ the initial applied stress, $\sigma_{0}=$ $100 \mathrm{MPa}), 100 \mathrm{kgf}(200 \mathrm{MPa}), 200 \mathrm{kgf}(400 \mathrm{MPa}), 250 \mathrm{kgf}(500 \mathrm{MPa})$ and $300 \mathrm{kgf}(600 \mathrm{MPa})$ at $T=708 \mathrm{~K}$.

$(\log \varepsilon-\log t)$ curves taken under various constant loads, $F$, of $50 \mathrm{kgf}$ (the initial applied stress, $\sigma_{0}=100 \mathrm{MPa}$ ), $100 \mathrm{kgf}$ (200 MPa), $200 \mathrm{kgf}(400 \mathrm{MPa}), 250 \mathrm{kgf}(500 \mathrm{MPa})$ and $300 \mathrm{kgf}(600 \mathrm{MPa})$ at $T=708 \mathrm{~K}$. The true strain, $\varepsilon$, was calculated with $\varepsilon=\Delta l / l_{0} \cdot\left(1+\Delta l / l_{0}\right)$, where $l_{0}$ and $\Delta l>0$ respectively are the initial sample length and displacement which is positive for compression mode. It is obvious that the larger the initial applied stress, the faster the deformation. The deformation behaviors can be divided into two modes depending on the initial applied stress. When $\sigma_{0}$ is less than a critical stress, $\sigma_{\mathrm{c}}(=\sim 150 \mathrm{MPa}$ at $t=0 \mathrm{~s})$, at a condition of the Newtonian flow prevails, e.g., $\sigma_{0}=100 \mathrm{MPa}$, the strain, $\log \varepsilon$, increases almost linearly with increasing time, $\log t$, then the strain rate decreases due to the nanocrystallizaztion. On the other hand, when $150 \mathrm{MPa}<\sigma_{0} \leq 600 \mathrm{MPa}$, the flow curves show a nonlinear viscoelasticity, softening phenomenon. For example, for $F=300 \mathrm{kgf}\left(\sigma_{0}=600 \mathrm{MPa}\right)$, the $\log \varepsilon$ increases linearly for $t \leq 5 \mathrm{~s}$, then increases rapidly. This increase in the strain rate suggests a transition from the Newtonian to non-Newtonian viscous flow. This phenomenon is considered to be due to stress-induced structural disordering and is followed by a decrease in strain rate due to structural recovering caused by a decrease in true stress. These softening and recovering phenomena have been observed in constant load compressions of a $\mathrm{Zr}_{55} \mathrm{Al}_{10} \mathrm{Ni}_{5} \mathrm{Cu}_{30}$ $\mathrm{BMG}$ in the glass transition region. ${ }^{19)}$ In the present work, in addition to these phenomena, the nanocrystallization effect is overlapped in deformation behavior. As shown in Fig. 5(b), these effects can be clearly appeared in the experimental 


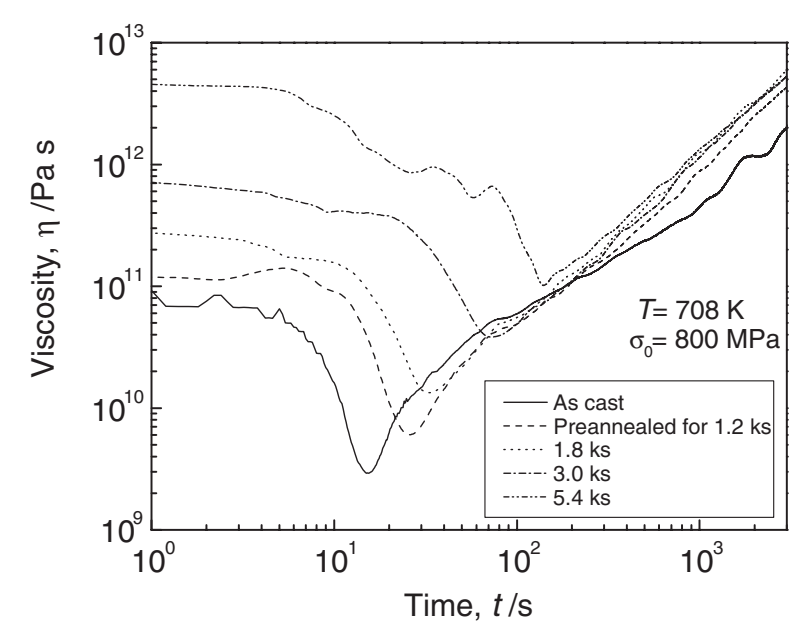

Fig. 6 Experimental viscosity-time $(\log \eta$ - $\log t)$ curves under a constant compressive load of $400 \mathrm{kgf}$ (the initial applied stress, $\sigma_{0}=800 \mathrm{MPa}$ ) of $\mathrm{Cu}_{60} \mathrm{Zr}_{30} \mathrm{Ti}_{10}$ bulk metallic glasses previously annealed isothermally at $T=708 \mathrm{~K}$ for 0 (= as-cast), 1.2, 1.8, 3.0 and $5.4 \mathrm{ks}$.

viscosity-time $(\log \eta-\log t)$ curves shown in Fig. 5(a). For $F=300 \mathrm{kgf}\left(\sigma_{0}=600 \mathrm{MPa}\right)$, the $\log \eta$ drastically decreases due to the stress-induced structural disordering, then, the flow structure reaches the equilibrium state at $t=31 \mathrm{~s}$ and it begins to recover to the initial state because true stress decreases with increasing strain due to an increase in cross section of the sample. If no crystallization occurs during the deformation, e.g., in the case for the thermally stable $\mathrm{Zr}_{55} \mathrm{Al}_{10} \mathrm{Ni}_{5} \mathrm{Cu}_{30} \mathrm{BMG}$, the structure finally returns back to the initial Newtonian state thus the corresponding viscosity becomes a constant as same value at $t=0$. But if crystallization occurs during deformation, viscosity increases and exceeds the initial value after the softening, e.g., curves at $F>75 \mathrm{kgf}\left(\sigma_{0}>150 \mathrm{MPa}\right)$ in Fig. 5(b).

\subsubsection{Dependence of constant-load deformation behav-} iors on pre-annealing time

Figure 6 shows the experimental viscosity-time $(\log \eta$ $\log t$ ) curves of $\mathrm{Cu}_{60} \mathrm{Zr}_{30} \mathrm{Ti}_{10}$ BMGs pre-annealed isothermally at $T=708 \mathrm{~K}$ for various times, $1.2,1.8,3.0$ and $5.4 \mathrm{ks}$. The applied load was fixed to $400 \mathrm{kgf}\left(\sigma_{0}=800 \mathrm{MPa}\right)$ for all curves. With increasing annealing time, the starting viscosity increases due to nanocrystallization. But all the curves once showed softening, transition to the nonlinear viscoelasticity, then followed by viscosity increase due to recovering to the linear viscoelasticity which is overlapped by the nanocrystallization effect. Here it is worth pointing out that viscosity drop due to the transition being a factor of twenty changes little with increasing the annealing time.

\subsection{Extension of the fictive stress model to nonlinear viscoelasticity with an in situ crystallization \\ 3.3.1 Fictive stress model}

For describing transition behaviors between the linear and nonlinear viscoelasticity in stable supercooled liquids, the fictive stress model was suggested by Chen et al. ${ }^{17)}$ This model is based on two hypothesizes below,

(1) For an applied stress, there exists an equilibrium structure of liquid.

(2) Structure of liquid is disordered (inducing free vol- umes) with an applied stress which is larger than the critical stress, and rate of structural change to equilibrium state is dominated by relaxation time of the structure.

With the fictive stress model, some kinds of experimental nonlinear viscoelasticity, such as stress-overshoot and following stress-oscillation under constant strain rate mode ${ }^{20-22)}$ and softening/recovering phenomena under constant compressive-load mode, ${ }^{20,24)}$ of the stable liquid were successfully reproduced. The relationship between an applied stress, $\sigma_{\mathrm{f}}$, and viscosity of the corresponding equilibrium structure, $\eta$, is expressed by,

$$
\frac{\sigma_{\mathrm{f}}}{\sigma^{*}}=\frac{\eta}{\eta_{\mathrm{N}}} \cdot\left[-\ln \left(1-\frac{\eta}{\eta_{\mathrm{N}}}\right)\right]^{-\beta},
$$

where $\eta_{\mathrm{N}}, \beta$ and $\sigma^{*}$ are respectively the Newtonian viscosity, an stretched exponent and the maximum stress which liquid can sustain at sufficiently high shear rate and depends only slightly on temperature. By eq. (2), the flow structure and corresponding normalized viscosity is connected to the normalized stress. This stress is named the fictive stress. The hypothesis (2) is so-called stress-inducing mechanism, and is expressed by,

$$
\frac{d \sigma_{\mathrm{f}}}{d t}=\frac{\sigma-\sigma_{\mathrm{f}}}{\lambda_{\mathrm{f}}}
$$

where $\lambda_{\mathrm{f}}$ is structural relaxation time. Using these equations and stress relaxation equation of the simple Maxwell model,

$$
\frac{d \sigma}{d t}=E \cdot \frac{d \varepsilon}{d t}-\frac{\sigma}{\tau_{\mathrm{f}}},
$$

where $\varepsilon, E$ and $\tau_{\mathrm{f}}$ respectively are strain, Young's modulus and stress relaxation time, the fictive stress model calculation can be conducted. In this work, $\lambda_{\mathrm{f}}$ is considered to be the same value with $\tau_{\mathrm{f}}$.

\subsubsection{Modifications for addition of an in situ crystalli- zation effect to the Fictive stress model}

(1) Newtonian viscosity, $\eta_{\mathrm{N}}$, to be a function of volume fraction, $\phi$, of time, $t$.

(2) The maximum stress, $\sigma^{*}$, to be a function of volume fraction, $\phi$, of $t$.

(3) Young's modulus, $E$, to be a function of volume fraction, $\phi$, of $t$.

Modifications for (1)-(3) are explained below.

The volume fraction of nanoparticles, $\phi$, is expressed by,

$$
\phi=\phi_{\mathrm{Q}}+\phi_{1},
$$

where $\phi_{\mathrm{Q}}$ and $\phi_{1}$ are respectively volume fraction of the $\mathrm{Cu}$ rich phase nanoparticles and of the phase precipitated in the metallic glass matrix by annealing. The $\phi_{1}$ can be related to the enthalpy of the first exothermic peak, $H$, on the DSC curves shown in Fig. 2(a), thus eq. (5) is modified to,

$$
\phi=\phi_{\mathrm{Q}}+\left(1-\frac{H}{H_{\text {total }}}\right) \cdot \phi_{\mathrm{M}},
$$

where $H_{\text {total }}$ and $\phi_{\mathrm{M}}$ are enthalpy of the whole reaction and the corresponding volume fraction of the first exothermic DSC peak.

Influence of dispersoids on viscosity of liquid, i.e., suspension, is well analyzed by the Mooney's law, 


$$
\ln \frac{\eta}{\eta_{0}}=\frac{k_{\mathrm{e}} \cdot \phi}{1-\frac{\phi}{\phi_{\mathrm{m}}}}
$$

where $\eta, \eta_{0}, k_{\mathrm{e}}$ and $\phi_{\mathrm{m}}$ are viscosity of the composite material, of the liquid without dispersoids, the Einstein coefficient and the maximum volume fraction of dispersoids. In the present work, as stated in section 3.1, nanoparticles (the $\mathrm{Cu}$-rich phase) have already existed at as-cast state and its volume fraction, $\phi_{\mathrm{Q}}$, is unknown. Thus $\eta_{0}$ is difficult to be estimated. The relationship between $\eta$ and $t$ without $\eta_{0}$ is obtained by subtracting eq. (6) at $\phi=\phi_{\mathrm{Q}} \eta=\eta_{\mathrm{Q}}$ from eq. (6), then using eqs. (1) and (5a)

$$
\ln \left(\frac{\eta}{\eta_{\mathrm{Q}}}\right)=\frac{k_{\mathrm{e}} \phi_{\mathrm{M}}\left[1-\exp \left(-K \cdot t^{n}\right)\right]+k_{\mathrm{e}} \phi_{\mathrm{Q}}}{1-\frac{\phi_{\mathrm{M}}}{\phi_{\mathrm{m}}}\left[1-\exp \left(-K \cdot t^{n}\right)\right]-\frac{\phi_{\mathrm{Q}}}{\phi_{\mathrm{m}}} \phi_{\mathrm{Q}}}, 1-\frac{\phi_{\mathrm{Q}}}{\phi_{\mathrm{m}}},
$$

in the present work, $k_{\mathrm{e}}=2.5$ (for spherical particle), $\phi_{\mathrm{m}}=$ $1.0, K=1.04 \times 10^{-3}$, and $n=0.78$ determined at the section 3.1. The experimental $\log \eta-\log t$ curve of $\sigma_{0}=$ $100 \mathrm{MPa}$ was fitted by eq. (6a) and the unknown parameters, $\phi_{\mathrm{Q}}$ and $\phi_{\mathrm{M}}$ are determined to be 0.26 and 0.79 , respectively.

Because the maximum stress, $\sigma^{*}$, is obtained at sufficiently high strain rate, the relaxation effect can be neglected. Therefore influence of nanoparticles on $\sigma^{*}$ is considered to be approximately expressed by the mixture law,

$$
\ln \sigma^{*}=\phi_{1} \ln \sigma_{\mathrm{p}}+\left(1-\phi_{1}\right) \ln \sigma_{0}^{*},\left(\phi_{1} \leq \phi_{\mathrm{M}}\right),
$$

where $\sigma_{\mathrm{p}}$ and $\sigma_{0}{ }^{*}$ are particle strength and maximum stress of the starting alloy $(t=0)$. Figure 7(a) shows the experimental viscosity-true stress $(\log \eta$ - $\log \sigma)$ curves of $\mathrm{Cu}_{60} \mathrm{Zr}_{30} \mathrm{Ti}_{10}$ BMGs pre-annealed isothermally at $T=708 \mathrm{~K}$ for various times, $t_{\mathrm{a}}=0,1.2,1.8,3.0$ and $5.4 \mathrm{ks}$ (corresponding conditions to Fig. 6) at the initial applied stress, $\sigma_{0}=$ $800 \mathrm{MPa}$. The true stress is calculated by $\sigma=\left(F / A_{0}\right)$. $\left(1-\Delta l / l_{0}\right), \Delta l>0$ for compression mode. From Fig. 7(a), a master curve at $t_{\mathrm{a}}=0$ is constructed in Fig. 7(b) with superimposing the curves of $t_{\mathrm{a}}=1.2,1.8,3.0$ and $5.4 \mathrm{ks}$ in the initial part of recovering process to that of $t_{\mathrm{a}}=0 \mathrm{ks}$ by horizontal shift, and dependence of shift factor, $a_{\mathrm{t}}$, on $t_{\mathrm{a}}$ is obtained in Fig. 7(b). The $\sigma^{*}{ }_{0}$ is estimated to $650 \mathrm{MPa}$ at the lowest viscosity, thus highest strain rate. The maximum stress, $\sigma^{*}$, of the curves of $t_{\mathrm{a}}=1.2,1.8,3.0$ and $5.4 \mathrm{ks}$ are approximately estimated to be $650,810,101$ and $1467 \mathrm{MPa}$, respectively by $\sigma^{*}=\sigma^{*}{ }_{0} \cdot a_{\mathrm{t}}$. These values are fitted by eq. (7a), and the $\sigma_{\mathrm{p}}$ is determined to $3.8 \mathrm{GPa}$.

Dependence of Young's modulus, $E$, on volume fraction of the nanoparticle is also approximately expressed by the mixture law,

$$
\ln E=\phi_{1} \ln E_{\mathrm{p}}+\left(1-\phi_{1}\right) \ln E_{0},\left(\phi_{1} \leq \phi_{\mathrm{M}}\right),
$$

where $E_{\mathrm{p}}$ and $E_{0}$ are Young' modulus of the particle and the starting alloy $(t=0)$, respectively. From the slope of the experimental stress-strain curves of the samples at $T=708 \mathrm{~K}$, $\dot{\varepsilon}=2.2 \times 10^{-2} \mathrm{~s}^{-1}$ (not shown here), Young's modulus of the samples are determined to be $12 \mathrm{GPa}$. And from the dependence of Young's modulus at room temperature on the volume fraction of the precipitates (not shown here), ${ }^{23)}$ the

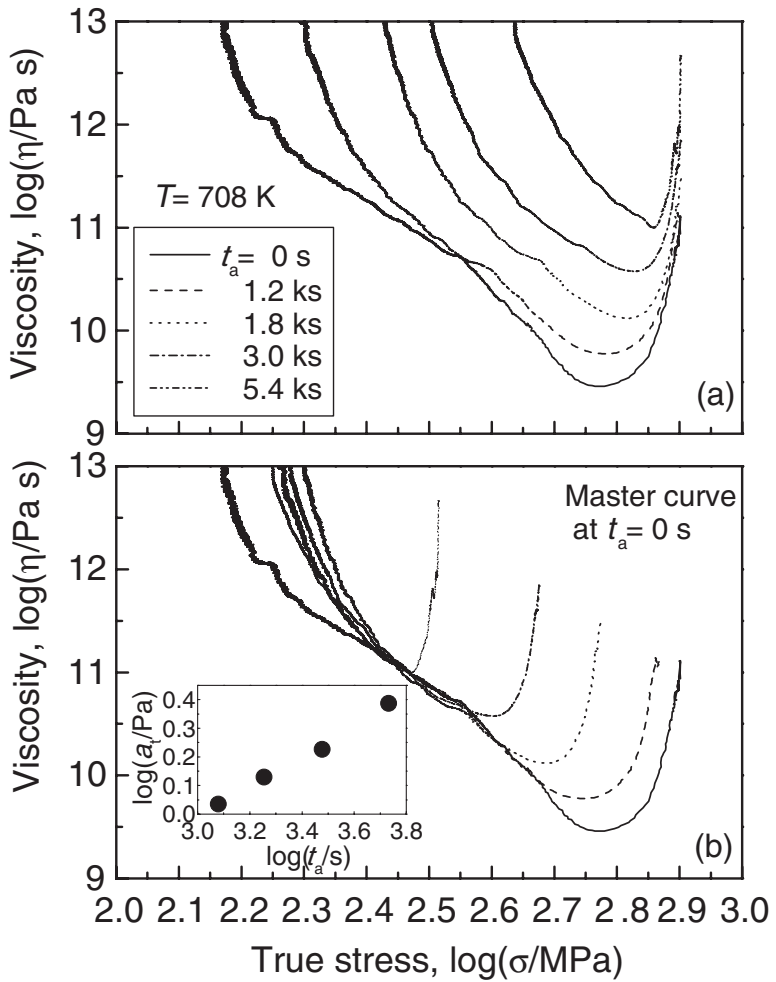

Fig. 7 Viscosity-true stress $(\log \eta$ - $\log \sigma)$ curves under a constant compressive load of $400 \mathrm{kgf}$ (the initial applied stress, $\sigma_{0}=800 \mathrm{MPa}$ ) of $\mathrm{Cu}_{60} \mathrm{Zr}_{30} \mathrm{Ti}_{10}$ bulk metallic glasses previously annealed isothermally at $T=708 \mathrm{~K}$ for 0 (= as-cast), 1.2, 1.8, 3.0 and 5.4 ks. (a) Master curve at the annealing time, $t_{\mathrm{a}}$, of $0 \mathrm{~s}$ of viscosity-true stress $(\log \eta-\log \sigma)$ curves (shown in Fig. 7(a)) (b). Dependence of the shift factor, $a_{\mathrm{t}}$, on the annealing time, $t_{\mathrm{a}}$, is inserted in Fig. 7(b).

$E_{\mathrm{p}}$ can be estimated to $128 \mathrm{GPa}$. Both the $\sigma_{\mathrm{p}}$ and $E_{\mathrm{p}}$ are deduced as fitting parameters based on eqs. (7) and (8), respectively. The true values of them are uncertain in this work.

Using eqs. (6a), (7), (8) and ordinary equations for the fictive stress model calculation, i.e., eqs. (2)-(4), the transition behaviors between the linear and nonlinear viscoelascitiy with the in situ nanocrystallization can be reproduced.

\subsection{Calculation results on compressive constant load deformations of the $\mathrm{Cu}_{60} \mathrm{Zr}_{30} \mathrm{Ti}_{10} \mathrm{BMG}$ at $T_{\mathrm{g}}$ by the extended fictive stress model}

Figures 8(a) and (b) show that calculated strain-time and viscosity-time curves of the initial applied stresses of 100 , 200, 400, 500 and $600 \mathrm{MPa}$, respectively. The calculated curves fairly reproduced the characteristics shown in the corresponding experimental curves in Fig. 5(b) such as the transition (softening-recovering) driven by stress, the hardening by the nanoprecipitation and their dependence on initial applied stress. In addition, although the peak time of the calculated curves tends to be underestimated, their peak viscosities are almost comparable to those in the corresponding experimental curves shown in Fig. 5(b). This difference is partially due to dependence of the $\beta$ which expresses the relaxation-time distribution during deformation on the volume fraction of the nanoprecipitates. With an increase in the volume fraction of the nanoprecipitates, the relaxationtime distribution is considered to become wider, thus the $\beta$ 


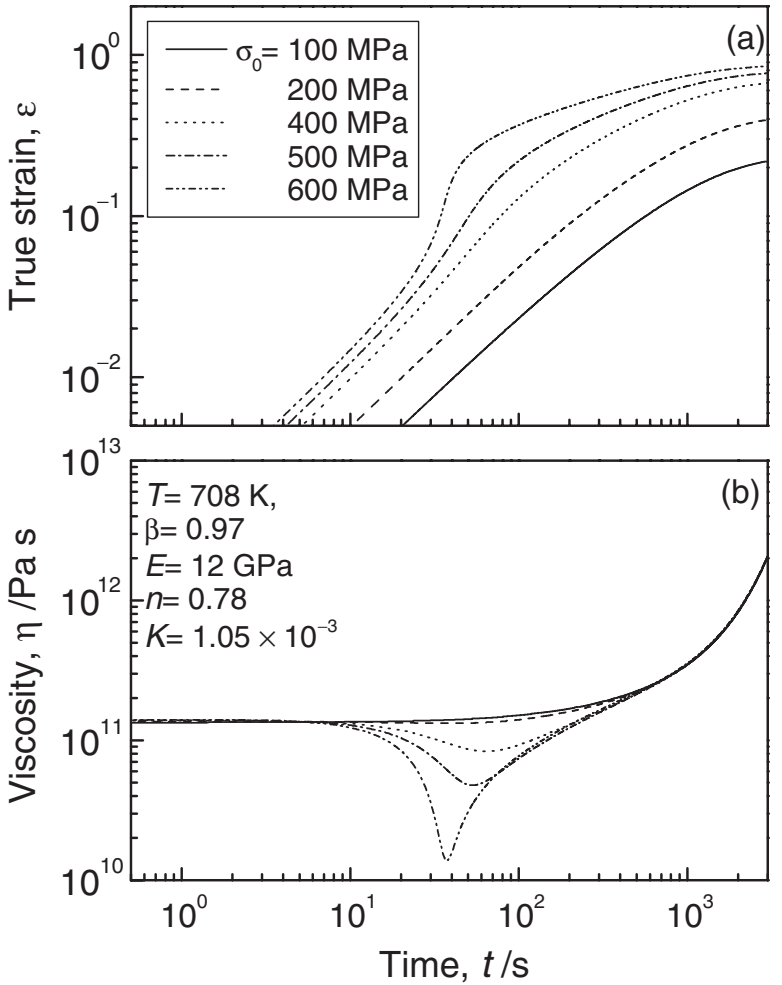

Fig. 8 Strain-time $(\log \varepsilon-\log t)$ (a) and viscosity-time $(\log \eta-\log t)$ (b) curves calculated with the extended fictive stress model calculated at the initial applied stresses of 100, 200, 400, 500 and $600 \mathrm{MPa}$ at $T=708 \mathrm{~K}$. The $\beta, E, n$ and $K$ are respectively the stretched exponent in eq. (2)), Young's modulus, the Avrami exponent and a fitting parameter in eq. (1).

becomes smaller than the initial value of $\sim 0.98$. This effect results in the delay of the transition process. As another possibility of the difference between the experimental and calculated curves, one can point out the crystallization enhancement by the nonlinear viscous flow because the viscous frictional loss brings about temperature raise ${ }^{24,26)}$ of the deforming sample. Further research and investigation on the influences of the nanoprecipitation on relaxation time distribution and of the nonlinear viscous flow on nanocrystallization would be of scientific and of technological importance, and may bring about more rigid calculations of the nonlinear viscoelasticity with the in situ nanocrystallization by the extended fictive stress model.

\section{Summary}

Mechanical response (e.g., stress, strain and viscosity) of a $\mathrm{Cu}_{60} \mathrm{Zr}_{30} \mathrm{Ti}_{10}$ bulk metallic glass (BMG) during the nonlinear viscoelasticity influenced by the in situ nanocrystallization under constant load compression at the onset temperature of the glass transition, $T_{\mathrm{g}}$, was investigated.

(1) The stress-driven softening and subsequent recovering phenomena were observed. But this transition was strongly influenced by the hardening due to the in situ nanoprecipitation of the unknown phase of $\sim 5 \mathrm{~nm}$ in diameter in the glassy matrix phase.

In order to add an in situ crystallization effect on calculations, the fictive stress model, which has successfully reproduced the nonlinear viscoelasticity in stable $\mathrm{Zr}-, \mathrm{Pd}-$ based bulk metallic glasses, was extended with the JohnsonMehl-Avrami method and mixture law for expressing increases in the Newtonian viscosity and in Young's modulus and the critical stress, respectively.

The extended fictive stress model fairly demonstrated the characteristics such as the transition phenomena (softeningrecovering) driven by stress, the hardening by the precipitation and their dependence on the initial applied stress under constant load compression. However, the calculated transition processes tend to be faster than those in the corresponding experimental curves. This may be due to the dependence of the relaxation time distribution on the volume fraction of the nanoparticles and also the crystallization enhancement by the nonlinear viscoelasticity.

\section{Acknowledgement}

This work was conducted under the Joint Research Project under the Japan-Korea basic Scientific Cooperation Program.

\section{REFERENCES}

1) A. Inoue, K. Ohtera, K. Kita and T. Masumoto: Jpn. J. Appl. Phys. 27 (1988) L2248.

2) A. Inoue, T. Zhang and T. Masumoto: Mater. Trans., JIM 30 (1989) 965.

3) A. Inoue, T. Zhang and T. Masumoto: Mater. Trans., JIM 31 (1990) 177.

4) A. Inoue, T. Shibata and T. Zhang: Mater. Trans., JIM 36 (1995) 1420

5) A. Peker and W. L. Johnson: Appl. Phys. Lett. 63 (1993) 2342-2344.

6) A. Inoue and J. S. Gook: Mater. Trans., JIM 36 (1995) 1180.

7) A. Inoue, N. Nishiyama and T. Matsuda: Mater. Trans., JIM 37 (1996) 1332.

8) A. Inoue, T. Zhang and T. Itoi: Mater. Trans., JIM 38 (1997) 359.

9) A. Inoue, T. Zhang and A. Takeuchi: Appl. Phys. Lett. 71 (1997) 464466.

10) A. Inoue, B. L. Shen, H. Koshiba, H. Kato and A. R. Yavari: Nature Mater. 2 (2003) 661-663.

11) C. Fan, A. Takeuchi and A. Inoue: Mater. Trans., JIM 40 (1999) 42-51.

12) A. Inoue, T. Zhang, M. W. Chen, T. Sakurai, J. Saida and M. Matsushita: J. Mat. Res. 15 (2000) 2195-2208.

13) A. Inoue, W. Zhang, T. Zhang and K. Kurosaka: Acta Mater. 49 (2001) $2645-2652$.

14) A. Inoue, W. Zhang, T. Zhang and K. Kurosaka: Mater Trans. 42 (2001) 1149-1151.

15) M. Kasai, J. Saida, M. Matsushita, T. Osuna, E. Matsubara and A. Inoue: J. Phys. Condens. Matter. 14 (2002) 13867-13877.

16) J. Saida, T. Osuna, M. Ohnuma, E. Matsubara and A. Inoue: Sci. Tech. Adv. Mater. 4 (2003) 311-318.

17) H. S. Chen, H. Kato and A. Inoue: Mater. Trans. 42 (2001) 597-605, ibid: Jpn. J. Appl. Phys. 39 (2000) 1808-1811.

18) W. A. Johnson and R. F. Mehl: Trans. AIME 135 (1939) 416-458.

19) D. V. Louzguine and A. Inoue: J. Mater. Res. 17 (2002) 2112-2120.

20) H. Kato, A. Inoue and H. S. Chen: Appl. Phys. Lett. 79 (2001) 45154517.

21) H. Kato, Y. Kawamura, A. Inoue and H. S. Chen: Mater. Trans., JIM 41 (2000) 1202-1207.

22) H. Kato, Y. Kawamura, H. S. Chen and A. Inoue: Jpn J. Appl. Phys. 39 (2000) 5184-5187.

23) J. Lu, G. Ravichandran and W. L. Johnson: Acta Mater. 51 (2003) 3429-3443.

24) H. S. Chen, H. Kato and A. Inoue: Mat. Res. Soc. Symp. Proc. 754 (2003) 219-230.

25) H. Kato, D. V. Louzguine, A. Inoue, H. S. Kim and S. I. Hong: J. Metastable and Nanocrystalline Mater. 15-16 (2003) 161-166.

26) H. Kato, A. Inoue and H. S. Chen: Appl. Phys. Lett. 84 (2003) 54015403. 